\title{
Smile to see the forest: Facially expressed positive emotions broaden cognition
}

\author{
Kareem J. Johnson, \\ Temple University, Philadelphia, Pennsylvania, USA \\ Christian E. Waugh, and \\ Stanford University, Stanford, California, USA \\ Barbara L. Fredrickson \\ University of North Carolina, Chapel Hill, North Carolina, USA
}

\begin{abstract}
The broaden hypothesis, part of Fredrickson's $(1998,2001)$ broaden-and-build theory, proposes that positive emotions lead to broadened cognitive states. Here, we present evidence that cognitive broadening can be produced by frequent facial expressions of positive emotion. Additionally, we present a novel method of using facial electromyography (EMG) to discriminate between Duchenne (genuine) and non-Duchenne (non-genuine) smiles. Across experiments, Duchenne smiles occurred more frequently during positive emotion inductions than neutral or negative inductions. Across experiments, Duchenne smiles correlated with self-reports of specific positive emotions. In Experiment 1, high frequencies of Duchenne smiles predicted increased attentional breadth on a global-local visual processing task. In Experiment 2, high frequencies of Duchenne smiles predicted increased attentional flexibility on a covert attentional orienting task. These data underscore the value of using multiple methods to measure emotional experience in studies of emotion and cognition.
\end{abstract}

\section{Keywords}

Broaden-and-build theory; Positive emotion; Duchenne smile; Attentional orienting; Global local; Holistic perception

\begin{abstract}
Beyond being a fertile research topic in psychology, the interaction of cognition and emotion is a familiar aspect of human experience. People often speak of how negative feelings can produce "tunnel vision", or of how optimists see the world through "rosecoloured lenses". These common sayings have been borne out by empirical research. Decades ago, Easterbrook (1959) suggested that states of anxiety narrow attentional focus by reducing the ability to process peripheral information. Negative emotional states and traits have been linked to narrowed attentional scope (Basso, Schefft, Ris, \& Dember, 1996; Derryberry \& Tucker, 1994), decreased attentional flexibility (Compton, 2000; Derryberry \& Reed, 2001), and attentional biases towards sources of threat (Bradley, Mogg, \& Millar, 2000; MacLeod \& Mathews, 1988; Öhman, Flykt, \& Esteves, 2001). By contrast, positive emotional states and traits have been linked to broadened attentional scope (Fredrickson \& Branigan, 2005; Gasper \& Clore, 2002; Rowe, Hirsch, \& Anderson, 2006; Schmitz, DeRosa,
\end{abstract}

(C) 2009 Psychology Press, an imprint of the Taylor \& Francis Group, an Informa business

Correspondence should be addressed to: Kareem J. Johnson, 518 Weiss Hall, Department of Psychology, Temple University, 1701 N. 13th St., Philadelphia, PA 19122, USA. kareem.johnson@temple.edu. 
\& Anderson, 2009), increased attentional flexibility (Compton, Wirtz, Pajoumand, Claus, \& Heller, 2004; Dreisbach \& Goschke, 2004), and enhanced ability to disengage attention from unpleasant stimuli (Isaacowitz, 2005; Sergerstrom, 2001).

The ability of emotions to bias how people attend to stimuli in their environment can have profound consequences for everyday functioning. Attentional biases linked to emotional states and dispositions have become an increasing focus of research on mood disorders like depression (Donaldson, Lam, \& Mathews, 2007; McCabe \& Gotlib, 1995; Nolen-

Hoeksema, Morrow, \& Fredrickson, 1993), generalised anxiety (Mogg \& Bradley, 2005), social anxiety (Clark \& Wells, 1995; Schultz \& Heimberg, 2008), and posttraumatic stress disorder (Bryant \& Harvey, 1995; Buckley, Blanchard, \& Trammell, 2000). Recent therapies that train patients to control relevant attentional biases have shown promise as effective treatments for a growing number of clinical disorders (Roemer \& Orsillo, 2009; Teasdale, 2004).

Even so, most research on cognitive and emotional interactions has examined the role of negative emotions in guiding attention and perception. In the past decade, however, an increasing amount of research has targeted the effects of positive emotional states on attention and perception. For example, Fredrickson's broaden-and-build theory $(1998,2001)$ proposed that although focusing and fixating attention can make negative emotions adaptive for facing short-term threats, positive emotions, in contrast, broaden attention and encourage cognitive flexibility that potentially enhances long-term survival. Over time, these moments of broadened cognition may help to build physical, psychological, and social resources.

Several lines of research support the hypothesis that positive emotions can broaden perceptual scope and increase holistic processing. Experiments using global-local visualprocessing tasks have found that negative emotional states and traits are associated with perceptual biases towards local features (Basso et al., 1996; Derryberry \& Reed, 1998; Gasper, 2004), while many positive emotional states and traits are associated with biases toward global configurations (Fredrickson \& Branigan, 2005; Gasper \& Clore, 2002). For instance, when presented with a composite figure (e.g., three squares arranged in a triangle formation), people high in trait anxiety focused more on the local features (i.e., the squares) whereas people high in trait optimism focused more on the global configuration (i.e., a triangle) when making perceptual judgements (Basso et al., 1996). Whereas Derryberry and Reed (1998) found that trait anxiety and aversive motivational states produced local perceptual biases on reaction-time-based global-local tasks, Fredrickson and Branigan (2005) found that global perceptual biases could be produced by eliciting positive emotional states through short film clips.

However, it is important to note that not all forms of positive emotion lead to broadened attention and perception. Gable and Harmon-Jones (2008) found that participants who viewed pictures of highly pleasant and desirable dessert foods showed a reduction in global bias on a global-local reaction time task compared to participants viewing neutral images. The narrowing effects became even more pronounced if participants believed that they could later consume the desserts. An increase in attentional focus and fixation could be very adaptive when trying to obtain an immediate and highly desirable goal. However, in situations where goals are more long term or more ambiguous, attentional breath and cognitive flexibility may be more advantageous.

Research on the interaction of emotional states and facial processing provide additional evidence that positive emotions can broaden perceptual scope. Facial recognition generally relies on holistic processing, but the faces of racial out-groups are often processing in a more featural or part-based way (Rhodes, Brake, Taylor, \& Tan, 1989; Tanaka, Kiefer, \& Bukach, 
2004). The lack of holistic processing applied to other-race faces may explain why otherrace faces are more difficult to recognise than same-race faces (Michel, Caldara, \& Rossion, 2006; Tanaka et al., 2004). However, Johnson and Fredrickson (2005) found that viewing a humorous video could improve recognition of out-group faces. Presumably, the induction of a positive emotional state allowed participants to process out-group faces as holistically as they would in-group faces. Recently, Curby, Johnson, and Tyson (2009) used a composite face task to measure changes in holistic face processing resulting from an emotion induction. They found that an anxiety induction reduced holistic processing of in-group and out-group faces relative to an amusement or neutral induction. Although they did not find a significant difference between the positive and the neutral induction, participants' selfreported increases in positive emotions like amusement, joy, gratitude, and hope were associated with increases in holistic processing.

Although Curby et al. (2009) found that reports of increased positive emotions lead to increased holistic processing, they also found that participants' responses to a positive emotion induction were more variable than responses to a negative emotion induction. Other researchers have found similar asymmetries in the effectiveness of positive and negative emotion inductions. Gasper and Clore (2002) had participants write about personal events in order to induce happy, sad, or neutral moods. Although they found that sad moods decreased global perceptions relative to happy moods, participants in the happy and neutral conditions did not differ in their reports of positive emotion. Similarly, Gasper (2004) found that a sad mood induction led to decreased global processing relative to a happy or a neutral induction, but her happy and neutral inductions did not produce any differences in mood or global processing relative to each other. She argued that it may be more difficult to induce positive emotions that generate observable effects relative to neutral states because the default state for most people is mildly positive (Diener \& Diener, 1996).

Customarily, the best indicator that someone is experiencing a significant amount of positive emotion is whether they are smiling. But, as Ekman and Friesen (1982) point out, not all smiles are indicators of true positive emotion. Smiles that indicate true feelings of enjoyment are referred to as "Duchenne" smiles (named after the French physiologist, Guillaume Duchenne de Boulogne, b. 1806-d. 1875). Duchenne smiles are involuntary and automatic facial expressions involving the simultaneous contraction of two facial muscles: the zygomaticus major, which pulls the corners of the mouth up and towards the ear; and the orbicularis oculi, pars lateralis, which raises the top of the cheek and wrinkles the outer corner of the eye (Ekman, Davidson, \& Friesen, 1990; Mark \& Ekman, 1993).

A large amount of research has confirmed that Duchenne smiles are an indicator of genuine enjoyment. In comparison to non-Duchenne smiles or other facial expressions, Duchenne ${ }^{1}$ smiles are more likely to be expressed in response to a pleasant film (Ekman, Friesen, \& O’Sullivan, 1988; Frank, Ekman, \& Friesen, 1993). Duchenne smiles are linked to higher self-reported feelings of enjoyment (Ekman et al., 1990; Soussignan, 2002). Ekman et al. (1990) found that Duchenne smiles expressed while watching pleasant film clips were associated with more left-sided brain activation, which has been linked to positive emotional traits and states (see Davidson, 1998). Ekman et al. (1988) tested nursing students ability to indicate that they were enjoying themselves while watching either a pleasant or an unpleasant video. They found that the presence of Duchenne smiles could be used to discriminate between genuine enjoyment and feigned enjoyment.

\footnotetext{
${ }^{1}$ In Ekman, Friesen, and O'Sullivan (1988) they use the term "felt smiles" instead of Duchenne smiles. In Ekman, Davidson, and Friesen (1990), the term is changed to "enjoyment smiles". In Frank, Ekman, and Friesen (1993) the terms "enjoyment smile" and "smile with Duchenne's marker" are used. Throughout this paper we will use the term "Duchenne smile".
} 
Up to this point, most research involving Duchenne smiles has relied on Ekman and Friesen's (1978) Facial Action Coding System (FACS) to record instances of Duchenne smiles. Although some new coding systems are beginning to gain popularity (e.g., FACES; see Kring \& Sloan, 2007), FACS is still one of the most widely used methods for coding facial expressions from videotaped recordings. Facial electromyography (EMG) offers an alternative method of detecting facial expressions (Dimberg, 1990; Fridlund \& Cacioppo, 1986). One advantage of facial EMG is that it can measure facial activity too subtle to observe visually (Cacioppo \& Petty, 1979; Tassinary \& Cacioppo, 1992). Facial EMG may also be able to index aspects of emotional experiences that may not be reflected in selfreports (Brown \& Schwartz, 1980; Vanman, Paul, Ito, \& Miller, 1997).

Most studies that have used facial EMG to assess emotional experience have focused on two facial muscles, the corrugator supercilii and the zygomaticus major. Activation of the corrugator supercilii pulls the brow down and inward, an action often described as a "furrowed brow". Several studies have demonstrated a linear and reciprocal relationship between corrugator supercilii activity and reports of subjective valence; corrugator supercilii activity increases during unpleasant experiences and decreases during pleasant experiences. Although only a few studies have found evidence that zygomaticus major activity decreases during unpleasant experiences (e.g., Cacioppo \& Petty, 1979), it has been widely shown that zygomaticus major activity increases during pleasant experiences (Cacioppo, Petty, Losch, \& Kim, 1986; Dimberg, 1997; Lang, Greenwald, Bradley, \& Hamm, 1993; Larsen, Norris, \& Cacioppo, 2003). However, there is reason to suspect that measuring the activity of zygomaticus major alone may be a problematic index of positive emotion. Recordings of the zygomaticus major may be susceptible to crosstalk because of the muscle's proximity to muscles involved in speaking and chewing (Tassinary \& Cacioppo, 2000). Although Lang et al. (1993) found that zygomaticus major activity was most commonly linked to viewing pleasant images, they also found that zygomaticus major could be reliably potentiated by some highly aversive pictures.

Even though Ekman and Friesen (1982) called for researchers to make greater distinctions between Duchenne and non-Duchenne smiles some time ago, only a few studies have measured activity of both orbicularis oculi and zygomaticus major during pleasant and unpleasant experiences (Cacioppo et al., 1986; Heponiemi, Ravaja, Elovainio, Naatanen, \& Keltikangas-Jarvinen, 2006; Surakka \& Hietanen, 1998). While these studies found activation of orbicularis oculi also increases during pleasant experiences, the activation of orbicularis oculi and zygomatic majoris were considered independently. As of now, we are aware of no studies that have used facial EMG to monitor the simultaneous activity of zygomaticus major and orbicularis oculi to index Duchenne smiles.

The purpose of Experiment 1 was to further examine the effects of induced emotions on holistic processing and attentional breadth. Holistic processing was measured with a reaction-time-based global-local task (modelled after a task used by Derryberry \& Reed, 1998). To examine potential effects of arousal in addition to valence, we induced four unique emotions (Joy: high valence/high arousal; Contentment: high valence/low arousal; Sadness: low valence/low arousal; and Anger: low valence/high arousal) plus a neutral state. We hypothesised that inducing positive emotions (regardless of arousal) would generate an increase in holistic processing relative to negative or neutral states. We also hypothesised that increases in holistic processing would be greatest for participants who experience the greatest increase in positive emotion. An additional purpose of Experiment 1 was to investigate the utility of using facial EMG activity from corrugator supercilii, orbicularis oculi, and zygomaticus major to index occurrences of Duchenne smiles, non-Duchenne smiles, and furrowed brows. In comparison to non-Duchenne smiles or furrowed brows, it was hypothesised that Duchenne smiles (as indexed by facial EMG) would occur more often 
in response to positive emotion inductions, that occurrences of Duchenne smiles would correlate with more self-reported positive emotions, and that more frequent Duchenne smiles would produce larger increases in holistic processing.

\section{EXPERIMENT 1}

\section{Method}

Participants-One hundred sixteen university undergraduates participated in the experiment in exchange for monetary compensation. Of these, $65 \%$ identified themselves as Caucasian, $10 \%$ as African American, $9 \%$ as East Asian, 5\% as South Asian, $4 \%$ as Hispanic/Latino, and $6 \%$ other or unspecified. Due to equipment failures (e.g., facial electrodes became detached, physiological recording failed to trigger), fourteen participants were eliminated from data analysis. An additional two participants were eliminated due to missing reaction-time data. The remaining sample consisted of 100 participants $(65 \%$ female).

Measures of dispositional affect-Several measures of participants' trait affectivity and baseline affect were given at the beginning of the experimental session. Trait optimism was assessed with the Life Orientation Test (LOT; Scheier \& Carver, 1985). A shortened version of Costa and McCrae's (1992) NEO Five Factor Inventory was used to assess trait levels of neuroticism, extraversion, and openness to new experiences. Levels of behavioural inhibition (BIS) and behavioural activation (BAS) were assessed with Carver and White's (1994) BIS/BAS scale. Emotional resiliency was assessed with the Ego-Resiliency scale (Block \& Kremen, 1996). Baseline levels of positive and negative affect were assessed with the Positive and Negative Affectivity Schedule (PANAS; Watson, Clark, \& Tellegren, 1988).

\section{Emotion-induction procedure}

Video stimuli: Brief video clips were used to induce the targeted emotions. Joy was induced with "Penguins" ( 2 min, $6 \mathrm{~s}$ ), a clip depicting wildlife footage of frolicking penguins accompanied by a humorous narration. Contentment was induced with "Nature" (1 min, 33 s), a clip showing scenic landscapes with soft music. Anger was induced with "Witness" (1 min, $40 \mathrm{~s}$ ), a clip depicting a person being unfairly treated by a group of hostile men. Sadness was induced with "Champ" ( 2 min, $6 \mathrm{~s}$ ), a clip of a child crying after the death of a loved one. Lastly, a neutral state was induced with "Sticks" (1 min, $33 \mathrm{~s}$ ), a clip showing abstract but dynamic patterns of brightly coloured lines.

Relived memories: Early in the experimental session, participants were asked to identify past personal experiences when they had strongly felt emotions. Immediately after the emotion-induction video, participants were asked to spend one minute vividly imagining the past emotional experience congruent with the emotion-induction video (adapted from Levenson, Carstensen, Friesen, \& Ekman, 1991). For the neutral emotion induction, participants were instructed to recall details of their daily morning routine.

\section{Emotion manipulation checks}

Emotion self-reports: Participants rated their subjective experiences during the emotioninduction video and the relived memory procedure (separately) with retrospective emotion reports (adapted from Ekman, Friesen, \& Ancoli, 1980). Participants indicated the degree to which they felt (on a 9-point scale from 0 to 8) ten specific emotions: amusement, anger, anxiety, contentment, disgust, fear, happiness, joy, sadness, and serenity. 
Facial EMG: Facial muscle activity was recorded using electromyography (EMG). Activity from corrugator supercilii, orbicularis oculi, and zygomaticus major was recorded during a 90-second physiological baseline and throughout the emotion-induction procedure (length varied by video). Electrodes were placed on the right side of participants' faces and followed guidelines set by Fridlund and Cacioppo (1986). Each muscle site was cleaned with alcohol and lightly abraded before placing two Med Associates $\mathrm{Ag} / \mathrm{AgCl}$ surface electrodes filled with electrolytic gel. For each muscle the inter-electrode distance was approximately 12 $\mathrm{mm}$. Across participants, the average inter-electrode impedance was less than $10 \mathrm{k} \Omega$. Bipolar electrical activity $(\mu \mathrm{V})$ at each muscle site was magnified with a SA Instruments bioamplifier and sampled at $1000 \mathrm{~Hz}$. EMG data were later rectified and processed using custom data acquisition and analysis software (James Long Inc.).

Use of facial EMG to index emotion-related facial activity-To index the frequency of emotion-related facial activity, we tallied the number of times each facial muscle was active during the emotion-induction procedure. First, EMG activity during the physiological baseline and emotion induction was averaged into 3-s bins. A muscle was considered "active" during the emotion induction if a bin's mean was greater than a specified activation threshold. By default, the activation threshold was set at two standard deviations above EMG activity recorded during the physiological baseline; however, threshold levels were manually adjusted for approximately $15 \%$ of participants with unusable baseline measures due to equipment failure, a high proportion of artefacts, or the participant failing to follow instructions to limit facial movements during baseline. Manually adjusted activation thresholds for each muscle were determined through visual inspection by a rater who was blind to the participant's emotion-induction condition. Thresholds were set to distinguish clusters of electromyographic activity from periods of relative inactivity during the emotion induction (see Cacioppo, Martzke, Petty, \& Tassinary, 1988, for a discussion of electromyographic clusters in comparison to other forms of facial EMG activity). Figure 1 provides an example of EMG data and thresholds used for scoring facial muscle activity.

For each 3-second bin during the emotion-induction procedure, a Duchenne smile was scored if zygomaticus major and orbicularis oculi were simultaneously active. The bin was only scored as a Duchenne smile if corrugator supercilii was simultaneously inactive to discriminate Duchenne smiles from general or non-specific facial activity. A non-Duchenne smile was scored for bins where zygomaticus major was active alone, without the simultaneous activation of either orbicularis oculi or corrugator supercilii. As a measure of negative emotion, we also tallied occurrences of "furrowed brows", when corrugator supercilii was the only active facial muscle (Larsen et al., 2003). To correct for varying lengths of the emotion inductions, counts were converted to percentages by dividing the number of active bins by the total number of bins per induction.

Global-local task-The stimuli for the global-local task were composite figures of a large letter " $T$ " composed of smaller " $T$ " figures. The objective of the global-local task was to detect whether an upright or inverted letter " $T$ " was present in the figure at either the global or the local level. Twelve different figures were used. Four figures contained global targets (upright $\mathrm{T}$ composed of Ts oriented left, upright $\mathrm{T}$ composed of Ts oriented right, inverted $\mathrm{T}$ composed of Ts oriented left, and inverted $\mathrm{T}$ composed of Ts oriented right). Four figures contained local targets (T oriented left composed of upright Ts, $\mathrm{T}$ oriented left composed of inverted Ts, T oriented right composed of upright Ts, and $\mathrm{T}$ oriented right composed of inverted Ts). The last four figures did not contain either global or local targets (T oriented right composed of Ts oriented left, T oriented right composed of Ts oriented right, T oriented left composed of Ts oriented left, and T oriented left composed of Ts oriented right). During the task, $25 \%$ of the trials presented global targets, $25 \%$ of the trials presented local targets, and the remaining $50 \%$ of trials presented no targets. No stimulus 
figure ever presented targets at both the global and local level. For each trial, participants were required to press one response button if a target was present and to press an alternate response button if no target was present. Each stimulus was presented until a response was made. There were a total of 192 trials with an inter-trial interval (ITI) of 1500 ms. A fixation cross was displayed during the ITIs. Responses were made with the first two fingers of the participant's dominant hand and reaction times were recorded with a stimulus-response box.

Procedure-At the start of the experimental session participants were given a questionnaire packet containing the measures of dispositional affect. The questionnaire packet also asked participants to indicate personal experiences of feeling joy, content, anger, and sadness. After the questionnaire packet was complete, the experimenter instructed participants on the global-local task. Participants were allowed to practise until they felt prepared to begin the task. After the practice trials, participants completed the global-local task as a baseline measure of attentional scope. Following the baseline global-local task, a physiological baseline was recorded. During the physiological baseline, participants were instructed to sit calmly and clear their thoughts for $90 \mathrm{~s}$. The physiological baseline was followed by the emotion-induction procedure. Participants first viewed a brief video clip selected to induce a joyful, content, neutral, angry, or sad emotional state. Immediately following the video clip, participants spent one minute visualising and re-living an emotional experience congruent with the video. Immediately following the relived memory, participants completed the global-local task a second time. After the global-local task, each participant completed two retrospective emotion reports to indicate how they felt while viewing the video and while reliving the memory, respectively.

\section{Results}

Dispositional affect prior to the emotion induction-In order to determine whether variations in dispositional affect were distributed equally across the inductions, one-way analyses of variance (ANOVAs) were performed for each measure. No significant differences in levels of optimism, neuroticism, extraversion, openness to experience, behavioural inhibition, behavioural activation, emotional resilience, positive affect, or negative affect were found between participants in the different emotion-induction conditions (all $F \mathrm{~s}<1$ ).

Self-reported emotions during the emotion induction-In order to determine whether the emotion inductions produced differences in self-reported emotions, one-way ANOVAs were performed for each emotion report item. Planned comparisons revealed significant differences for all ten emotion report items as a function of the emotion inductions. Positive emotion inductions (joy, contentment) produced significantly higher reports of positive emotion during the video and relived memory than the negative or neutral inductions. Similarly, the negative emotion inductions (anger, sadness) produced higher reports of negative emotions than the positive or neutral inductions (see Table 1 for means and pairwise statistics by induction).

\section{Frequencies of Duchenne smiles, non-Duchenne smiles, and furrowed brows}

-As expected, participants receiving the joy and contentment inductions expressed higher frequencies of Duchenne and lower frequencies of furrowed brows than those in the anger, sadness, or neutral inductions. Participants receiving the positive emotion inductions also expressed higher frequencies of non-Duchenne smiles. Across inductions, there was a higher prevalence of furrowed brows than either Duchenne or non-Duchenne smiles. However, the sadness induction resulted in significantly higher frequencies of furrowed brows relative to the other emotion inductions (see Table 1 for means and pairwise statistics by induction). 
Correlations of facial activity and self-reported emotions-As shown in Table 2, both Duchenne and non-Duchenne smiles were strongly correlated with self-reports of positive emotions like amusement, happiness, joy, contentment, and serenity during the emotion induction. Reports of sadness were correlated with lower frequencies of Duchenne smiles and higher frequencies furrowed brows.

Correlations of facial activity with dispositional affect-Across inductions, ${ }^{2}$ higher levels of extraversion and openness to new experiences were correlated with higher frequencies of Duchenne smiles. Duchenne smiles were also correlated with higher levels of baseline positive affect. No significant correlations were found for non-Duchenne smiles or furrowed brows with any of the dispositional affect measures (see Table 2).

Global-local task performance-To rule out undue influence of outliers on mean reaction times, excessively slow $(>1500 \mathrm{~ms})$ or fast $(<100 \mathrm{~ms})$ reaction times were removed from analysis (Heijden, 1992); less than $1 \%$ of the data were excluded by this procedure. Participant responses were accurate $96 \%$ across all trials and only reaction times from correct responses were analysed.

Three different indexes of attentional scope were calculated: (1) changes in global target recognition; (2) changes in local target recognition; and (3) changes in global bias (relatively faster recognition of global over local targets). Each of these indexes was calculated by subtracting baseline reaction times from experimental reaction times. Lower values thus represent improved (faster) responding following the emotion-induction procedures.

Effects of emotion induction on changes in attentional scope-Randomly assigned emotion inductions were not predictive of changes in attentional scope. A 5 (Emotion Induction: joy, content, neutral, anger, sad) $\times 2$ (Task Time: pre-induction vs. post-induction) repeated-measures ANOVA found no significant main effects or interactions for changes in global target recognition, changes in local target recognition, or changes in global bias as a function of the emotion inductions (all $F_{\mathrm{s}}<1$ ).

Correlations of self-reported emotions with changes in attentional scopeSelf-reported emotions were not predictive of changes in attentional scope. No significant correlations emerged between self-reported emotions and changes in global target recognition, local target recognition, or global bias (see Table 2).

Correlations of trait affectivity and baseline affect with changes in attentional scope-Trait affectivity and baseline affect were not predictive of changes in attentional scope. No significant correlations emerged between levels of trait affectivity or baseline affect and changes in global target recognition, local target recognition, or global bias (see Table 2).

\footnotetext{
${ }^{2}$ In order to explore whether dispositional affect had different effects on facial activity for positive or negative inductions, we conducted additional analyses on the two positive inductions (joy, content) collapsed together $(N=46)$ and the two negative inductions (anger, sadness) collapsed together $(N=44)$. For the positive emotion inductions, Duchenne smiles were correlated with trait levels of extraversion $(r=.39, p<.02)$ and openness to new experience $(r=.36, p<.02)$. Baseline positive affect and the remaining measures of dispositional affect were not correlated with Duchenne smiles during the positive emotion inductions. Unexpectedly, baseline levels of negative affect were correlated with frequencies of Duchenne smiles during the negative emotion inductions $(r=.40, p<.02)$. No significant correlations emerged for any measures of dispositional affect with non-Duchenne smiles or furrowed brows during the positive or the negative inductions. Although the relatively small sample size of the neutral condition makes correlations more prone to error, results from the neutral induction were similar to negative inductions, with higher levels of baseline negative affect being correlated with more Duchenne smiles during the neutral induction.
} 
Correlations of facial activity with changes in attentional scope-Consistent with our hypothesis, across the inductions ${ }^{3}$ the frequency of Duchenne smiles was significantly correlated with changes in global target recognition $(r=-.32, p<.001)$ and changes in global bias $(r=-.29, p<.01)$. There were no significant correlations between changes in attentional scope and frequencies of non-Duchenne smiles or furrowed brows.

To further explore the relationship between the frequency of Duchenne smiles and changes in global bias, we entered both linear and quadratic terms in a regression model predicting change in global bias. Only the quadratic curve remained significant $(B=-.54, t=-2.06, p$ $<.05)$, suggesting hat improvements in holistic processing only occurred for those participants who frequently expressed positive emotions. In order to illustrate this quadratic relationship, regardless of their assigned emotion inductions, participants who never expressed any Duchenne smiles during the emotion induction were placed into a "no smiles" group, participants who expressed Duchenne smiles less than $10 \%$ of the time were placed in a "few smiles" group, and participants who expressed Duchenne smiles $10 \%$ of the time or more were placed into a "frequent smiles" group. As shown in Figure 2, participants in the frequent smiles group showed a larger change in global bias compared to the few smiles, $t(97)=-2.23, p<.03$, or the no smiles group, $t(97)=-2.43, p<.03$.

\section{Discussion}

The results from Experiment 1 reveal a novel twist on the relationship between positive emotions and attention. Although the emotion inductions were largely effective in eliciting levels of targeted positive emotions, neither the inductions themselves nor self-reports of positive emotion predicted changes in attentional breadth. Instead, the only measure found to be related to changes in attentional breadth was facial activity during the emotion induction. Participants who frequently expressed Duchenne smiles during the emotion induction became significantly faster at recognising global targets relative to local targets. Although the results of Experiment 1 suggest that dispositional traits like extraversion and openness to new experience may have made some participants more likely to express Duchenne smiles, the dispositional traits themselves were not related to changes in attentional breadth. ${ }^{4}$ The results of Experiment 1 suggest that frequent facial expressions of positive emotion promotes more efficient holistic processing.

The association between Duchenne smiles and broadened attentional breadth was not linear. Rather this relationship was only present in people expressing genuine smiles at high frequency. It may be the case that a certain frequency of expressed positive emotion was required to generate detectable levels of broadened cognition on the global-local reactiontime task. Importantly, evidence of broadened cognition was limited to facial activity related to Duchenne smiles and not to general facial activity. Although non-Duchenne smiles were also strongly correlated with self-reported positive emotion, non-Duchenne smiles did not predict any changes in attentional breadth.

\footnotetext{
${ }^{3}$ In order to explore whether changes in attentional scope were correlated with the frequency of Duchenne smiles during either positive or negative emotion inductions, we conducted separate analyses for the positive and negative emotion inductions. Restricting analyses to the positive emotion inductions, Duchenne smiles remained correlated with global bias $(r=-.48, p<.001)$ and global target recognition $(r=-.36, p<.02)$. However, when analyses were restricted to the negative emotion inductions, Duchenne smiles were not correlated with changes in attentional scope. This is not surprising due to the fact that Duchenne smiles rarely occurred during the negative emotion inductions.

${ }^{4}$ Quite unexpectedly, we also found that participants whose moods were more negative at the start of the experiment were more likely to smile during a negative emotion induction. It is unclear why this should be the case. However, we could speculate that perhaps these participants may have experienced some type of contrast effect. For instance, participants in a bad mood may have found the anger-induction video slightly enjoyable.
} 
Although facially expressed positive emotion broadened attentional breadth, we did not find evidence that facially expressed negative emotion narrowed attentional breadth. Instances of furrowed brows were not associated with improved recognition of local targets or a reduction in global bias. It was expected that our measure of furrowed brows would be an indicator of general negative affect, however, in the present experiment, the highest frequencies of furrowed brows were linked most strongly to the sadness induction and selfreported levels of sadness. Across all emotion inductions, furrowed brows were more prevalent than smiles, perhaps due to generalised corrugator supercilii activity associated with the concentration and effort of recalling and reliving a past memory (Cacioppo, Petty, $\&$ Morris, 1985).

The results of Experiment 1 highlight the potential utility of using facial EMG when conducting research on emotion and cognition. Here we presented one method of using facial EMG to code for instances of Duchenne smiles, non-Duchenne smiles, and furrowed brows. Our measure of Duchenne smiles appeared to be a reliable measure of positive emotional responding. As predicted, Duchenne smiles were more frequent during positive emotion inductions than negative or neutral inductions, and Duchenne smiles were correlated with self-reports of positive emotions.

The results of Experiment 1 suggest that frequent displays of positive emotion are associated with broadened cognition, in this case, more efficient holistic processing. Frequent smiling enhanced the ability to recognise global configurations over local details, or, metaphorically, seeing the "forest" over the "trees". Broadened cognition, however, can take forms other than enhanced holistic perceptions. Several studies have linked affective states to changes in attentional control and flexibility (Derryberry \& Reed, 2001; Jefferies, Smilek, Eich, \& Ens, 2008). For instance, negative affect has been linked to decreased ability to shift attentional focus during orienting tasks (Compton, 2000; Compton et al., 2004). The work of Compton and colleagues has demonstrated that decreased attentional flexibility is particularly associated with reduced levels of positive affect; however, we are aware of no research clearly demonstrating an association between increased attentional flexibility and high levels of positive affect.

The purpose of Experiment 2 was to examine whether experimentally induced positive emotions and/or Duchenne smiles (as indexed by facial EMG) would predict increases in attentional flexibility on a task of attentional orienting. Attentional flexibility was measured with a covert attentional orienting task (modelled after the task used by Compton, 2000). Participants were asked to detect the appearance of a peripheral target while fixating on a central point. Usually, the target was preceded by a cue that either appears in the same location (valid cue) or in a different location (invalid cue) as the target. High performance on this attentional orienting task required an ability to flexibly shift attention to valid cues while being able to divert attention away from invalid cues.

Because it was believed that a simplified induction procedure might more effectively generate cognitive effects, Experiment 2 used a different emotion induction from Experiment 1. The induction used in Experiment 2 required participants to read affective statements while listening to an emotionally congruent piece of music. Three types of emotional states were induced; elation/joy, anger, or a neutral state. Additionally, Experiment 2 employed a different emotion self-report measure that surveyed a wider range of emotions. Although Experiment 2 did not include measures of dispositional trait affectivity, changes in emotion were monitored by comparing emotion reports completed before and after the induction. 
As in Experiment 1, we hypothesised that induced positive emotions would increase attentional flexibility and that increases in attentional flexibility would be larger for participants who experience a larger increase in positive emotion. Furthermore, we hypothesised that occurrences of Duchenne smiles would occur more frequently during a positive induction, that occurrences of Duchenne smiles would correlate with self-reported positive emotions, and that more frequent Duchenne smiles would predict increases in attentional flexibility.

\section{EXPERIMENT 2}

\section{Method}

Participants-Sixty-two college students (60\% female) completed the study in exchange for monetary compensation. Of the sample, $64 \%$ identified themselves as Caucasian, $8 \%$ as African American, $10 \%$ as East Asian, 5\% as South Asian, $8 \%$ as Hispanic/Latino, and 5\% as other or unspecified. Due to incomplete physiological $(N=7)$, or reaction time data $(N=$ $2)$, nine participants were excluded from analyses, resulting in a final sample of 51 (51\% female).

\section{Emotion-induction procedure}

Mood-induction statements: An induction procedure adapted from Velten $(1968)^{5}$ was used to elicit states of elation, anger, or neutrality. Each participant read a series of 25 selfreferential statements, shown for $15 \mathrm{~s}$ each, chosen to elicit the assigned state. For instance, to induce a positive state of joy or elation participants read statements like "I feel really great today". After the statements, participants spent one minute reflecting on their feelings to intensify the emotion (Sinclair, Mark, Enzle, Borkovec, \& Cumbleton, 1994).

Mood-induction music: To augment the emotion inductions, the statements were accompanied by a congruent musical selection shown in past research to also elicit the targeted emotions. Participants who read the elation statements heard Bach's "Brandenburg Concerto" (Bower \& Mayer, 1989), those who read the anger statements heard "From Mars, The Planets" by Holst (Mayer, Allen, \& Beauregard, 1995), and those who read the neutral statements heard "Nocturne, \#62" by Chopin (Bower \& Mayer, 1989).

\section{Emotion manipulation checks}

Differential Emotions Scale (DES): A modified version of the Differential Emotions Scale (original DES, Izard, 1977; modified DES, Fredrickson, Tugade, Waugh, \& Larkin, 2003) was used to measure self-reported emotions prior to and after the induction. Participants indicated how much they felt each of 18 different emotions (amusement, anger, awe, compassion, contempt, contentment, disgust, embarrassment, fear, gratitude, guilt, hope, interest, joy, love, pride, sadness, and shame. Each emotion item was described with three descriptors, for example "glad, happy, joyful' or "angry, irritated, annoyed'. Participants rated their subjective experience of each emotion a 5-point scale $(0=$ "not at all"; $4=$ "extremely"). On the first DES, participants indicated how they felt at that moment. On the second DES, participants indicated how they felt during the emotion induction.

\footnotetext{
${ }^{5}$ The Velten statements were modified from the original Velten statements. Eighteen of the neutral statements and 24 of the elation statements were from the original Velten (1968) set. The remaining seven neutral statements and one elation statement were from Seibert and Ellis (1991). All of the anger statements were from Engebretson, Sirota, Niaura, Edwards, and Brown (1999). We carefully selected those elation and anger statements that did not specifically reference attentional capabilities, or cognitive effort. For the neutral statements, we omitted those statements that were concerned with geographical information, so as to not prime participants with cues that called their attention to a broadened perspective of their environment.
} 
Facial EMG: Similar to Experiment 1, facial EMG activity was recorded from corrugator supercilii, orbicularis oculi, and zygomaticus major throughout the emotion-induction procedure and a physiological baseline. Electrode placement procedures and psychophysiological recording equipment were identical to Experiment 1.

Covert attentional orienting task-Originally developed by Posner (1980), the attentional orienting task was modelled after Compton (2000). The computer monitor was positioned approximately $80 \mathrm{~cm}$ from the participant. Reaction times were recorded with a stimulus-response box. During the task, three boxes were displayed, a central box containing a fixation cross and boxes positioned $10^{\circ}$ to the left and right of fixation. Each box subtended approximately a $1.3^{\circ} \times 1.3^{\circ}$ area of visual angle.

Participants' primary task was to make a response whenever they detected a target inside one of the lateral boxes. The target was a small $\left(0.9^{\circ} \times 0.9^{\circ}\right)$ solid black box. On uncued trials, the target simply appeared in one of the lateral boxes. On cued trials, one of the lateral boxes became bold for $250 \mathrm{~ms}$, which signalled that the target would appear inside one of the lateral boxes moments later. The target remained until a response was made. A stimulus onset asynchrony (SOA) of either 100 or $500 \mathrm{~ms}$ separated the cue and the target. On valid cue trials, the target appeared in the same location as the cue, whereas on invalid cue trials the target appeared in the other lateral box. The orienting task had 400 trials, of which, one third (132 trials) were uncued. Within cued trials, one third used invalid cues (88 trials) and two thirds used valid cues (190 trials). Interspersed throughout were 40 "catch" trials, in which a cue was given without an accompanying target. Additionally, interspersed throughout were 40 fixation-check trials, in which a number between 1 and 9 was displayed for $50 \mathrm{~ms}$ at the fixation point. Participants were required to report the number aloud. With "catch" trials and fixation checks, the attentional orienting task was 480 total trials. A 1second delay separated each trial.

Procedure-At the start of the experimental session, participants completed a survey of demographic information and the first DES. The experimenter then instructed participants on the covert attentional orienting task. Participants were allowed to practise until they felt prepared to begin the task. After the practice trials, participants completed the attentional orienting task as baseline measure of attentional scope. Next, a physiological baseline was recorded for 90 seconds. For the physiological baseline, participants were instructed to sit calmly and clear their thoughts during which facial EMG activity was recorded. Participants then went through the emotion-induction procedure. Lastly, participants did the covert attentional orienting task a second time and completed the second DES.

\section{Results}

Change in self-reported emotions by emotion induction-In order to determine whether the emotion inductions were effective at eliciting emotions, we calculated change scores by subtracting DES ratings made prior to the induction from ratings made after the induction. Although ANOVA comparisons revealed several significant changes in emotion reports as a function of the emotion, overall the emotion inductions were less effective than anticipated. The elation induction produced a decrease in reports of some negative emotions and the anger induction produced a decrease in reports of some positive emotions, however neither induction produced substantial increases in targeted emotions (see Table 3 for means and pairwise comparisons).

Frequencies of Duchenne smiles, non-Duchenne smiles, and furrowed brows -Duplicating the analyses ${ }^{6}$ used in Experiment 1, facial EMG data were coded for occurrences of Duchenne smiles, non-Duchenne smiles, and furrowed brows. As with 
Experiment 1, raw counts of Duchenne smiles were converted into percentages to keep estimates consistent across experiments. The elation induction resulted in lower frequencies of furrowed brows relative to the neutral and anger inductions. However, there were no significant differences in frequencies of Duchenne or non-Duchenne smiles as a function of the emotion inductions (see Table 3 for means and pairwise statistics).

Correlations of facial activity with self-reported emotions-In order to explore the relationship between facial activity and self-reported emotion, we correlated Duchenne smiles, non-Duchenne smiles, and furrowed brows with DES ratings made after the induction, controlling for ratings made prior to the induction. As shown in Table 4, Duchenne smiles were associated with increased reports of hope and contentment, nonDuchenne smiles were associated with increased reports of pride and awe, and furrowed brows were associated with increased reports of shame.

Covert attentional orienting task performance-Excessively slow ( $>1500 \mathrm{~ms})$ or fast (< $100 \mathrm{~ms})$ RTs were removed to eliminate slow responses due to inattentiveness or fatigue, and fast responses due to anticipatory errors (Heijden, 1992). Fewer than $2 \%$ of responses were eliminated by this procedure. Similar to Compton et al. (2004), we were not interested in the "inhibition of return" attentional mechanism prevalent at longer SOAs, and so only responses to $100 \mathrm{~ms}$ SOA trials were analysed.

Three indices of attentional performance were calculated from the valid, invalid, and uncued trial types. Attentional benefits were calculated by subtracting valid-cue reaction times from uncued reaction times. Higher scores indicate relatively faster responding resulting from the attentional cue. Attentional costs were calculated by subtracting uncued reaction times from invalid-cue reaction times. Higher scores indicate relatively slower responding resulting from an invalid distracter. Validity effect was calculated by subtracting valid-cue reaction times from invalid-cue reaction times. The validity effect is a measure of how much attentional orienting is influenced by cueing. Higher times indicate greater fixation to the cue while lower times indicate greater flexibility in shifting attention regardless of cue (Posner, 1980; Posner \& Peterson, 1990; Witte, Davidson, \& Marrocco, 1997).

To determine the impact of the emotion inductions, emotion self-reports, and facial activity on changes in attentional orienting, baseline performance on the covert attentional orienting task was subtracted from performance following the emotion inductions. The following analyses were performed on difference scores indexing changes in attentional benefits, changes in attentional costs, and changes in validity effect.

Effects of emotion induction on changes in attentional orienting-Assigned emotion inductions did not predict changes in attentional orienting. A 3 (Emotion Induction: elation, neutral, anger) $\times 2$ (Task Time: pre-induction vs. post-induction) repeated-measures ANOVA found no significant main effects or interactions for changes in attentional benefits, attentional costs, or validity effect as a function of the emotion inductions (all $F \mathrm{~s}<1$ ).

\section{Correlations of self-reported emotions with changes in attentional orienting-}

In order to explore the relationship between changes in attentional orienting and selfreported emotion, we correlated changes in attentional costs, attentional benefits, and validity effect with DES ratings made after the induction, controlling for DES ratings made prior to the induction. As shown in Table 4, decreases in validity effect were correlated with

\footnotetext{
${ }^{6}$ As with Experiment 1, muscle activation thresholds were manually adjusted for approximately $15 \%$ of participants because of unusable or unstable physiological baselines. These errors in the physiological baseline were due to equipment failures or to muscle artefacts produced by participants failing to follow instructions to sit calmly during the baseline.
} 
increased reports of joy, hope, interest, and pride and increases in validity effects were correlated with increased reports of shame and guilt. In addition, reports of joy, gratitude, and awe were correlated with decreases in attentional costs.

Correlations of facial activity with changes in attentional orienting-Consistent with our hypothesis, higher frequencies of Duchenne smiles were correlated with significant decreases in validity effect $(r=-.42, p<.005)$ and marginal decreases in attentional costs $(r$ $=-.26, p<.06)$. No significant correlations emerged for changes in attentional costs, attentional benefits, or validity effect with non-Duchenne smiles or with furrowed brows (all $p \mathrm{~s} n s)$.

Regression analyses revealed a significant quadratic relationship between frequency of Duchenne smiles and reductions in the validity effect. When the linear and quadratic terms were simultaneously entered into the model, only the quadratic curve remained significant $(B=-.74, t=-2.31, p<.03)$. This quadratic relationship is similar to that found in Experiment 1 and suggests that attentional flexibility was increased only for participants who smiled frequently.

As with Experiment 1, to illustrate this quadratic relationship, participants who never expressed any Duchenne smiles during the emotion induction were placed into a "no smiles" group, participants who expressed Duchenne smiles less than 10\% of the time were placed in a "few smiles" groups, and participants that expressed Duchenne smiles $10 \%$ of the time or more were placed into a "frequent smiles" group. As shown in Figure 3, participants in the frequent smiles group showed a greater change in validity effect relative to the few smiles group, $t(50)=-2.41, p<.03$, and the no smiles group, $t(50)=-2.27, p<.03$.

\section{Discussion}

The results of Experiment 2 extend the findings from Experiment 1 and show Duchenne smiles, as indexed by facial EMG, are associated with increased attentional flexibility. Although the randomly assigned emotion inductions did not predict changes in attentional performance, self-reported and facially expressed positive emotions did predict significant increases in attentional flexibility. Higher frequencies of Duchenne smiles during the emotion induction were linked to decreased attentional costs and decreased validity effect relative to baseline task performance. This change in performance indicates that Duchenne smiles were associated with the participants' ability to disengage their attention from irrelevant distracters. These results complement previous research that found increases in the validity effect were linked to low levels of positive affect and greater distress in response to negative emotion inductions (Compton, 2000; Compton et al., 2004). The present findings, in combination with the findings of Compton and colleagues, suggest that increases in positive emotion are accompanied by increases in attentional flexibility.

Similar to Experiment 1, evidence of broadened cognition was found for participants who displayed frequent Duchenne smiles. Relative to non-smilers, those smiling only a few times had negligible improvements in attentional flexibility; however, frequent smilers showed significant improvements in attentional flexibility. Again, the benefits of smiling only occurred for indicators of genuine positive emotions. Non-Duchenne smiles and furrowed brows were not associated with changes in any of the attentional orienting measures.

Unlike Experiment 1, self-reported levels of positive emotion also predicted broadened cognition. This may reflect greater sensitivity afforded by surveying a wider range of emotions and obtaining emotion reports before and after the emotion inductions. For instance, after controlling for emotions reported prior to the induction, the only emotion report item associated with both Duchenne smiles and attentional flexibility was hope, 
which was not surveyed in Experiment 1. The results of Experiment 2 again highlight the utility of multiple methods for measuring emotions. Although the assigned emotion inductions did not predict attentional changes, facial EMG and a more comprehensive emotion self-report scale were able to find significant links between positive emotions and attentional flexibility.

\section{GENERAL DISCUSSION}

Taken together, the results of Experiments 1 and 2 provide evidence that positive emotions forecast broadened cognition, namely, holistic processing and attentional flexibility. Notably, even though the findings are correlational, these two indices of broadened cognition represent changes from baseline cognitive processing. These changes from baseline cognitive performance suggests that frequent smilers were not dispositionally more likely to show improved levels of holistic processing and attentional flexibility, instead it appears that expressing Duchenne smiles played a role in eliciting broadened cognitive states.

The results of the present experiments have provided consistent evidence that Duchenne smiles are associated with states of broadened cognition. The links uncovered between Duchenne smiles and broadened cognition appear to have been carried by participants who expressed high frequencies of Duchenne smiles relative to participants who never smiled or only smiled a few times (see Figure 2 and Figure 3). These results suggest that broadened cognitive states may require a certain frequency of experiencing, or at least facially expressing, genuine positive emotion (Diener, Sandvik, \& Pavot, 1990). It is possible that previous studies finding mixed or weak broadening effects may not have elicited sufficient instances of positive emotion to produce the effects. The mixed effectiveness of emotion inductions used in the current paper confirms the difficulties of reliably inducing high levels of targeted emotions. It is also possible that previous studies finding mixed or weak effects may not have been able to adequately measure the amount of positive emotion being experienced by participants.

The current paper underscores the advantages of using multiple methods to index emotions (Larsen \& Fredrickson, 1999). In comparison to assigned emotion inductions and selfreports, Duchenne smiles, as indexed by facial EMG, emerged as the most consistent predictor of cognitive broadening. However, it is not our intent to claim that facial EMG offers a superior measure of emotional experience, but instead to suggest facial EMG as an alternative measure that may be able to capture aspects of emotions not reflected in selfreports. Likewise, emotion self-reports may index aspects of emotions not reflected by facial expressions. As an example, although Ekman once referred to Duchenne smiles as "felt smiles", he soon decided to change the term to "enjoyment smiles" acknowledging that participants may express Duchenne smiles without ever being aware that they are smiling (Ekman, 1989).

Here, we have demonstrated a method for using facial EMG to discriminate between occurrences of Duchenne and non-Duchenne smiles. Our method of scoring was intended to be a fairly conservative estimate of Duchenne smiles. We restricted our definition of Duchenne smiles to only include instances when corrugator supercilii was inactive. Although this restriction provided a more specific measure of facially expressed positive emotion, we acknowledge that we may have underestimated the true number of Duchenne smiles by disqualifying some instances when laughter or surprise may have added corrugator supercilii activation. We scored instances when corrugator supercilii was the only active muscle as "furrowed brows" to measure general levels of negative affect. Although furrowed brows were related to reports of some negative emotions (sadness in Experiment 1 
and shame in Experiment 2), furrowed brows were not correlated with measures of attentional breadth or flexibility. However, the lack of results with the attentional measures may be due to aspects of the emotion-induction procedures. The inductions used in Experiments 1 and 2 required participants to mentally generate or relive emotional feelings. Because corrugator supercilii activity is also linked with mental effort and concentration (Cacioppo et al., 1985), our measure of furrowed brows may not have adequately discriminated true negative affect from mental effort.

The finding that Duchenne smiles and broadened cognition were linked to specific positive emotions like joy and hope may offer insight into how momentary states of broadened cognition could build personal resources. Positive affective traits like hope and optimism have been widely shown to contribute to better outcomes and life success (Lyubomirsky, King, \& Diener, 2005). In times of crises, people who report feelings like hope cope better with adversity than those who report only negative emotions (Fredrickson et al., 2003). The ability of emotionally resilient people to take a broad perspective and see a "silver lining" makes them faster to recover from stress and better able to solve life's problems (Fredrickson \& Joiner, 2002; Tugade \& Fredrickson, 2004). However, the results of the present studies suggest that the cognitive benefits of positive emotions are not limited to people who are optimistic and resilient. Instead the results suggest cognitive broadening is generated by being able to experience and/or express positive emotions in the moment.

Recently, in a test of the build hypothesis, Fredrickson and colleagues trained adults to cultivate positive emotions like love, hope, compassion, and gratitude through a daily loving-kindness meditation. Daily meditation not only increased daily experiences of positive emotion, but the intervention was also causally linked to significant improvements in physical resources, mental resources, and social resources over a nine-week period (Fredrickson, Cohn, Coffey, Pek, \& Finkel, 2008). One notable study suggests that expressions of Duchenne smiles may be especially predictive of better long-term outcomes. Using longitudinal data spanning several decades, Harker and Keltner (2001) found that women who had expressed Duchenne smiles in their college yearbook photos were more likely to get married, to stay married, to have higher marital satisfaction, and to have better subjective well-being than women whose yearbook smiles were feigned.

There is a quote by the English politician and poet Joseph Addison (b. 1672-d. 1719) that states, "What sunshine is to flowers, smiles are to humanity. These are but trifles ... but, scattered along life's pathway, the good they do is inconceivable". The results of the current experiments illustrate some of the ways that smiles may nurture personal growth and plant seeds for a better life. By promoting broader perspectives and more flexible thinking, the benefits of smiling are much more than "rose-coloured lenses". Rather, smiling seeds an expansive mindset that may be a vital contributor to health and well-being over the long term.

\section{Acknowledgments}

This research was supported by grants awarded from the National Institute of Mental Health (MH53971 and MH59615) and by Templeton Positive Psychology Prize (2000) awarded to BLF by the American Psychological Association.

We'd like to thank Tor Wager and Matthew Keller for their contribution to early data collection and analyses.

\section{REFERENCES}

Basso MR, Schefft BK, Ris MD, Dember WN. Mood and global-local visual processing. Journal of the International Neuropsychological Society. 1996; 2:249-255. [PubMed: 9375191] 
Block J, Kremen AM. IQ and ego-resiliency: Conceptual and empirical connections and separateness. Journal of Personality and Social Psychology. 1996; 70:349-361. [PubMed: 8636887]

Bower GH, Mayer JD. In search of mood-dependent retrieval. Journal of Social Behavior \& Personality, Special Issue. Mood and Memory: Theory Research and Applications. 1989; 4:121156.

Bradley BP, Mogg K, Millar NH. Covert and overt orienting of attention to emotional faces in anxiety. Cognition and Emotion. 2000; 14:789-808.

Brown S, Schwartz GE. Relationships between facial electromyography and subjective experience during affective imagery. Biological Psychology. 1980; 11:49-62. [PubMed: 7248403]

Bryant RA, Harvey AG. Processing threatening stimuli in post-traumatic stress disorder. Journal of Abnormal Psychology. 1995; 104:537-541. [PubMed: 7673578]

Buckley TC, Blanchard EB, Trammell NW. Information processing and PTSD: A review of the empirical literature. Clinical Psychology Review. 2000; 20:1041-1065. [PubMed: 11098399]

Cacioppo JT, Martzke JS, Petty RE, Tassinary LG. Specific forms of facial EMG response index emotions during an interview: From Darwin to the continuous flow hypothesis of affect-laden information processing. Journal of Personality and Social Psychology. 1988; 54:592-604. [PubMed: 3367281]

Cacioppo JT, Petty RE. Attitudes and cognitive response: An electrophysiological approach. Journal of Personality and Social Psychology. 1979; 37:2181-2199.

Cacioppo JT, Petty RE, Losch ME, Kim HS. Electromyographic activity over facial muscle regions can differentiate the valence and intensity of affective reactions. Journal of Personality and Social Psychology. 1986; 50:260-268. [PubMed: 3701577]

Cacioppo JT, Petty RE, Morris KJ. Semantic, evaluative, and self-referent processing: Memory, cognitive effort, and somatovisceral activity. Psychophysiology. 1985; 22:371-384. [PubMed: 4023148]

Carver S, White TL. Behavioral inhibition, behavioral activation, and affective responses to impending reward and punishment: The BIS/BAS scales. Journal of Personality and Social Psychology. 1994; 2:319-333.

Clark, DM.; Wells, A. A cognitive model of social phobia. In: Heimberg, RG.; Liebowitz, MR.; Hope, DA.; Schneier, FR., editors. Social phobia: Diagnosis, assessment and treatment. New York: Guilford Press; 1995. p. 69-93.

Compton RJ. Ability to disengage attention predicts negative affect. Cognition and Emotion. 2000; 14:401-415.

Compton RJ, Wirtz D, Pajoumand G, Claus E, Heller W. Association between positive affect and attentional shifting. Cognitive Therapy and Research. 2004; 28:733-744.

Costa, PT.; McCrae, RR. Revised NEO Personality Inventory (NEO-PI-R) and NEO Five-Factor Inventory (NEO-FFI) professional manual. Odessa, FL: Psychological Assessment Resources; 1992.

Curby, K.; Johnson, KJ.; Tyson, A. Perceptual expertise has an emotional side: Holistic face processing is modulated by observers' emotional state. Poster presented at the annual meeting of the Visual Sciences Society; Naples, Florida. 2009 May.

Davidson RJ. Anterior electrophysiological asymmetries, emotion, and depression: Conceptual and methodological conundrums. Psychophysiology. 1998; 35:607-614. [PubMed: 9715104]

Derryberry D, Reed MA. Anxiety and attentional focusing: Trait, state, and hemispheric influences. Personality and Individual Differences. 1998; 25:745-761.

Derryberry, D.; Reed, MA. A multidisciplinary perspective on attentional control. In: Folk, C.; Gibson, B., editors. Attraction, distraction, and action: Multiple perspectives on attentional capture. Amsterdam: Elsevier; 2001. p. 325-347.

Derryberry, D.; Tucker, DM. Motivating the focus of attention. In: Neidenthal, PM.; Kitayama, S., editors. The heart's eye: Emotional influences in perception and attention. San Diego, CA: Academic Press; 1994. p. 167-196.

Diener E, Diener C. Most people are happy. Psychological Science. 1996; 7:181-185. 
Diener, E.; Sandvik, E.; Pavot, WG. Happiness is the frequency, not intensity of positive versus negative affect. In: Strack, F.; Argyle, M.; Schwarz, N., editors. The social psychology of subjective well-being. Elmsford, NY: Pergamon Press; 1990. p. 119-139.

Dimberg U. Facial electromyography and emotional reactions. Psychophysiology. 1990; 27:481-494. [PubMed: 2274612]

Dimberg U. Facial reactions: Rapidly evoked emotional responses. Journal of Psychophysiology. 1997; 11:115-123.

Donaldson C, Lam D, Mathews A. Rumination and attention in major depression. Behavior Research and Therapy. 2007; 45:2664-2678.

Dreisbach G, Goschke T. How positive affect modulates cognitive control: Reduced perseveration at the cost of increased distractibility. Journal of Experimental Psychology: Learning, Memory, and Cognition. 2004; 30:343-353.

Easterbrook JA. The effect of emotion on cue utilization and the organization of behaviour. Psychological Review. 1959; 66:183-201. [PubMed: 13658305]

Ekman, P. The argument and evidence about universals in facial expressions of emotion. In: Wagner, H.; Manstead, A., editors. Handbook of psychophysiology: The biological psychology of emotions and social processes. Chichester, UK: Wiley; 1989. p. 143-164.

Ekman P, Davidson RJ, Friesen WV. The Duchenne smile: Emotional expression and brain physiology II. Journal of Personality and Social Psychology. 1990; 58:342-353. [PubMed: 2319446]

Ekman, P.; Friesen, WV. The Facial Action Coding System. Palo Alto, CA: Consulting Psychologists Press; 1978.

Ekman P, Friesen WV. Felt, false, and miserable smiles. Journal of Nonverbal Behavior. 1982; 6:238252.

Ekman P, Friesen WV, Ancoli S. Facial signs of emotional experience. Journal of Personality and Social Psychology. 1980; 39:1124-1134.

Ekman P, Friesen WV, O'Sullivan M. Smiles when lying. Journal of Personality and Social Psychology. 1988; 54:414-420. [PubMed: 3361418]

Engebretson TO, Sirota AD, Niaura RS, Edwards K, Brown WA. A simple laboratory method for inducing anger: A preliminary investigation. Journal of Psychosomatic Research. 1999; 47:13-26. [PubMed: 10511418]

Frank MG, Ekman P, Friesen WV. Behavioral markers and recognizability of the smile of enjoyment. Journal of Personality and Social Psychology. 1993; 64:83-93. [PubMed: 8421253]

Fredrickson BL. What good are positive emotions? Review of General Psychology. 1998; 2:300-319. [PubMed: 21850154]

Fredrickson BL. The role of positive emotions in positive psychology: The broaden-and-build theory of positive emotions. American Psychologist. 2001; 56:218-226. [PubMed: 11315248]

Fredrickson BL, Branigan C. Positive emotions broaden the scope of attention and thought-action repertoires. Cognition and Emotion. 2005; 19:313-332. [PubMed: 21852891]

Fredrickson BL, Cohn MA, Coffey KA, Pek J, Finkel SM. Open hearts build lives: Positive emotions, induced through loving-kindness meditation, build consequential personal resources. Journal of Personality and Social Psychology. 2008; 95:1045-1062. [PubMed: 18954193]

Fredrickson BL, Joiner T. Positive emotions trigger upward spirals towards emotional well-being. Psychological Science. 2002; 13:172-175. [PubMed: 11934003]

Fredrickson BL, Tugade MM, Waugh CE, Larkin G. What good are positive emotions in crises? A prospective study of resilience and emotions following the terrorist attacks on the United States on September 11th, 2001. Journal of Personality and Social Psychology. 2003; 91:904-917.

Fridlund AJ, Cacioppo JT. Guidelines for human electromyographic research. Psychophysiology. 1986; 23:567-589. [PubMed: 3809364]

Gable PA, Harmon-Jones E. Approach-motivated positive affect reduces breadth of attention. Psychological Science. 2008; 19:476-482. [PubMed: 18466409]

Gasper K. Do you see what I see? Affect and visual information processing. Cognition and Emotion. $2004 ; 18: 405-421$. 
Gasper K, Clore G. Attending to the big picture: Mood and global versus local processing of visual information. Psychological Science. 2002; 13:34-40. [PubMed: 11892776]

Harker L, Keltner D. Expression of positive emotion in women's college yearbook picture and their relationship to personality and life outcomes across adulthood. Journal of Personality and Social Psychology. 2001; 80:112-124. [PubMed: 11195884]

Heijden, AHC. Selective attention in vision. London: Routledge; 1992.

Heponiemi T, Ravaja N, Elovainio M, Naatanen P, Keltikangas-Jarvinen L. Experiencing positive affect and negative affect during stress: Relationships to cardiac reactivity and to facial expressions. Scandinavian Journal of Psychology. 2006; 47:327-337. [PubMed: 16987201]

Isaacowitz DM. The gaze of the optimist. Personality and Social Psychology Bulletin. 2005; 31:407415. [PubMed: 15657455]

Jefferies LN, Smilek D, Eich E, Ens JT. Emotional valence and arousal interact with attentional control. Psychological Science. 2008; 19:290-295. [PubMed: 18315803]

Johnson KJ, Fredrickson BL. "We all look the same to me": Positive emotions eliminates the own-race bias in face recognition. Psychological Science. 2005; 16:875-881. [PubMed: 16262774]

Kring AM, Sloan DM. The Facial Expression Coding System (FACES): Development, validation, and utility. Psychological Assessment. 2007; 19:210-224. [PubMed: 17563202]

Lang PJ, Greenwald MK, Bradley MM, Hamm AO. Look at pictures: Affective, facial, visceral, and behavioral reactions. Psychophysiology. 1993; 30:261-273. [PubMed: 8497555]

Larsen JT, Norris CJ, Cacioppo JT. Effects of positive and negative affect on electro-myographic activity over zygomaticus major and corrugator supercilii. Psychophysiology. 2003; 40:776-785. [PubMed: 14696731]

Levenson RW, Carstensen LL, Friesen WV, Ekman P. Emotion, physiology, and expression in old age. Psychology and Aging. 1991; 6:28-35. [PubMed: 2029364]

Lyubomirsky S, King L, Diener E. The benefits of frequent positive affect: Does happiness lead to success? Psychological Bulletin. 2005; 131:798-807.

MacLeod C, Mathews A. Anxiety and the allocation of attention to threat. Quarterly Journal of Experimental Psychology. 1988; 40:653-670. [PubMed: 3212208]

Mark FG, Ekman P. Not all smiles are created equal: The differences between enjoyment and nonenjoyment smiles. Humor: International Journal of Humor Research. 1993; 6:9-26.

Mayer JD, Allen JP, Beauregard K. Mood inductions for four specific moods: A procedure employing guided imagery vignettes with music. Journal of Mental Imagery. 1995; 19:151-159.

McCabe SB, Gotlib IH. Selective attention and clinical depression: Performance on a deployment of attention task. Journal of Abnormal Psychology. 1995; 104:241-245. [PubMed: 7897048]

Michel C, Caldara R, Rossion B. Same-race faces are perceived more holistically than other-race faces. Visual Cognition. 2006; 14(1):55-73.

Mogg K, Bradley BP. Attentional bias in generalized anxiety disorder versus depressive disorder. Cognitive Therapy and Research. 2005; 29:29-45.

Nolen-Hoeksema S, Morrow J, Fredrickson BL. Response styles and the duration of episodes of depressed mood. Journal of Abnormal Psychology. 1993; 102:20-28. [PubMed: 8436695]

Öhman A, Flykt A, Esteves F. Emotion drives attention: Detecting the snake in the grass. Journal of Experimental Psychology: General. 2001; 130(3):466-478. [PubMed: 11561921]

Posner MI. Orienting of attention. Quarterly Journal of Experimental Psychology. 1980; 32:3-25. [PubMed: 7367577]

Posner MI, Peterson SE. The attention system of the human brain. Annual Review of Neuroscience. 1990; 13:25-42.

Rhodes G, Brake S, Taylor K, Tan S. Expertise and configural coding in face recognition. British Journal of Psychology. 1989; 80:313-331. [PubMed: 2790391]

Roemer, L.; Orsillo, S. Mindfulness- and acceptance-based behavioral therapies in practice. New York: Guilford Press; 2009.

Rowe G, Hirsch JB, Anderson AK. Positive affect increases the breadth of attentional selection. Proceedings of the National Academy of Sciences, USA. 2006; 104:383-388. 
Scheier MF, Carver CS. Optimism, coping, and health: Assessment and implications of generalized outcome expectancies. Health Psychology. 1985; 4:219-247. [PubMed: 4029106]

Schmitz TW, DeRosa E, Anderson AK. Opposing influences of affective state valence on visual cortical encoding. Journal of Neuroscience. 2009; 29:7199-7207. [PubMed: 19494142]

Schultz LT, Heimberg RG. Attentional focus in social anxiety disorder: Potential for interactive processes. Clinical Psychology Review. 2008; 28:1206-1221. [PubMed: 18555570]

Seibert PS, Ellis HC. A convenient self-referencing mood induction procedure. Bulletin of the Psychonomic Society. 1991; 29:121-124.

Sergerstrom SC. Optimism and attentional bias for negative and positive information. Personality and Social Psychology Bulletin. 2001; 2:1334-1343.

Sinclair SE, Mark MM, Enzle ME, Borkovec TD, Cumbleton AG. Toward a multiple-method view of mood induction: The appropriateness of a modified Velten mood induction technique and the problems of procedures with group assignment to conditions. Basic \& Applied Social Psychology. 1994; 15:389-408.

Soussignan R. Duchenne smile, emotional experience, and autonomic reactivity: A test of the facial feedback hypothesis. Emotion. 2002; 2:52-74. [PubMed: 12899366]

Surakka V, Hietanen JK. Facial and emotional reactions to Duchenne and non-Duchenne smiles. International Journal of Psychophysiology. 1998; 29:23-33. [PubMed: 9641245]

Tanaka JW, Kiefer M, Bukach CM. A holistic account of the own-race effect in face recognition: Evidence from a cross-cultural study. Cognition. 2004; 93(1):B1-B9. [PubMed: 15110726]

Tassinary LG, Cacioppo JT. Unobservable facial actions and emotion. Psychological Science. 1992; 3:28-33.

Tassinary, LG.; Cacioppo, JT. The skeletomotor system: Surface electromyography. In: Cacioppo, JT.; Tassinary, LG.; Berntson, GG., editors. Handbook of psychophysiology. 2nd ed.. New York: Cambridge University Press; 2000. p. 163-199.

Teasdale, J. Mindfulness-based cognitive therapy. In: Yiend, J., editor. Cognition, emotion, and psychopathology: Theoretical, empirical, and clinical directions. New York: Cambridge University Press; 2004. p. 270-289.

Tugade MM, Fredrickson BL. Resilient individuals use positive emotions to bounce back from negative emotional experiences. Journal of Personality and Social Psychology. 2004; 86:320-333. [PubMed: 14769087]

Vanman EJ, Paul BY, Ito TA, Miller N. The modern face of prejudice and structural features that moderate the effect of co-operation on affect. Journal of Personality and Social Psychology. 1997; 73:941-959. [PubMed: 9364754]

Velten E. A laboratory task for the induction of mood states. Behaviour Research and Therapy. 1968; 6:473-482. [PubMed: 5714990]

Watson D, Clark LA, Tellegen A. Development and validation of brief measures of positive and negative affect: The PANAS scales. Journal of Personality and Social Psychology. 1988; 54:10631070. [PubMed: 3397865]

Witte EA, Davidson MC, Marrocco RT. Effects of altering brain cholinergic activity on covert orienting of attention: Comparison of monkey and human performance. Psychopharmacologia. 1997; 132:324-334. 


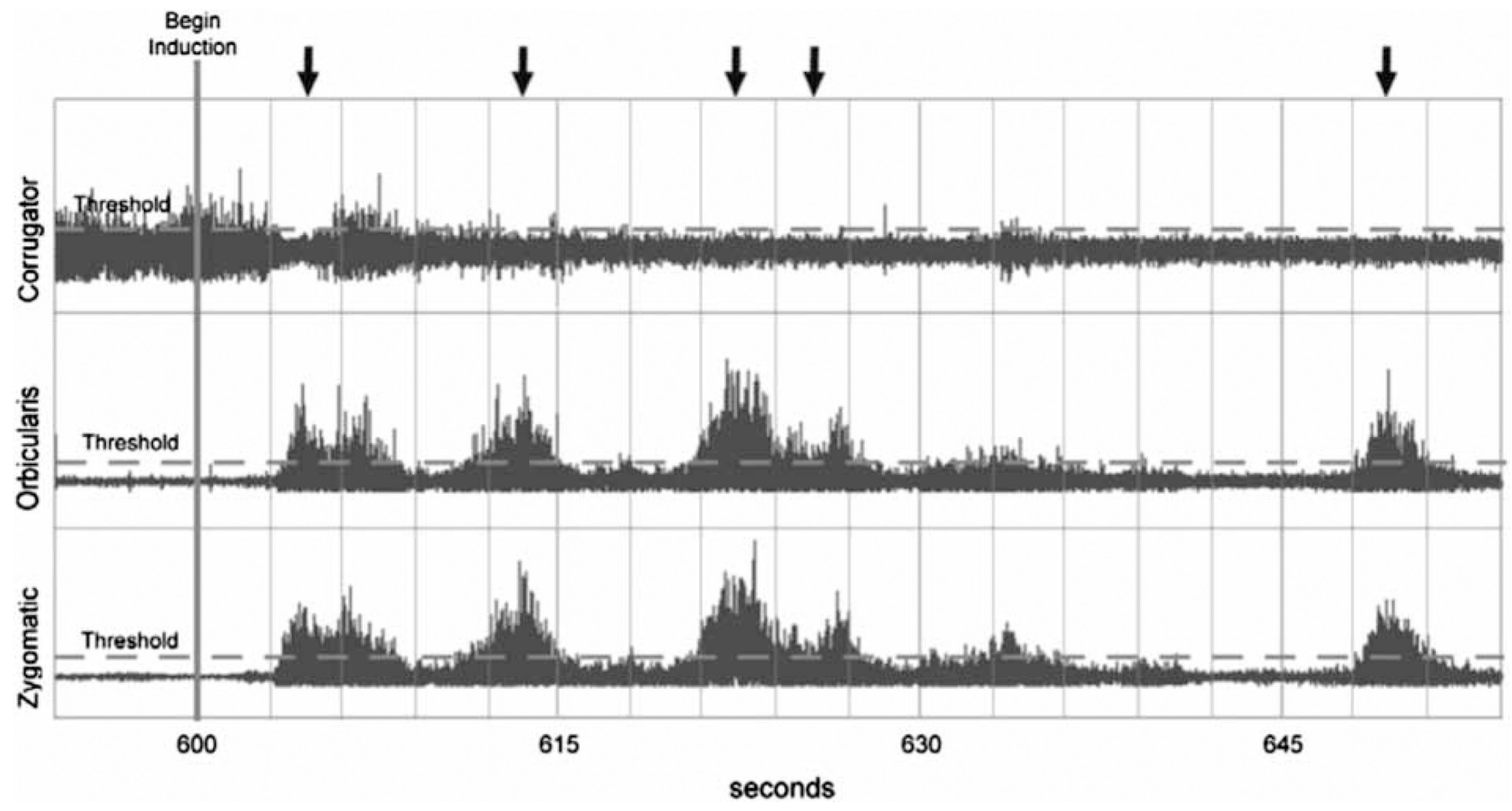

Figure 1.

Sample corrugator supercilii, orbicularis oculi, and zygomatic majoris activity during a positive emotion induction. For purposes of scoring, EMG recordings were divided into 3second bins. For each bin, a muscle was scored as active if its mean activity was greater than a baseline threshold. A Duchenne smile was scored when zygomatic majoris and orbicularis oculi were simultaneously activated while corrugator supercilii remained inactive. A nonDuchenne smile was scored when zygomatic majoris was the only muscle active. A furrowed brow was scored for bins in which corrugator supercilii was the only active muscle. The above example depicts a high frequency (approximately 28\%) of Duchenne smiles during the first minute of an emotion induction. Arrows at the top of the figure indicate bins scored as Duchenne smiles. 


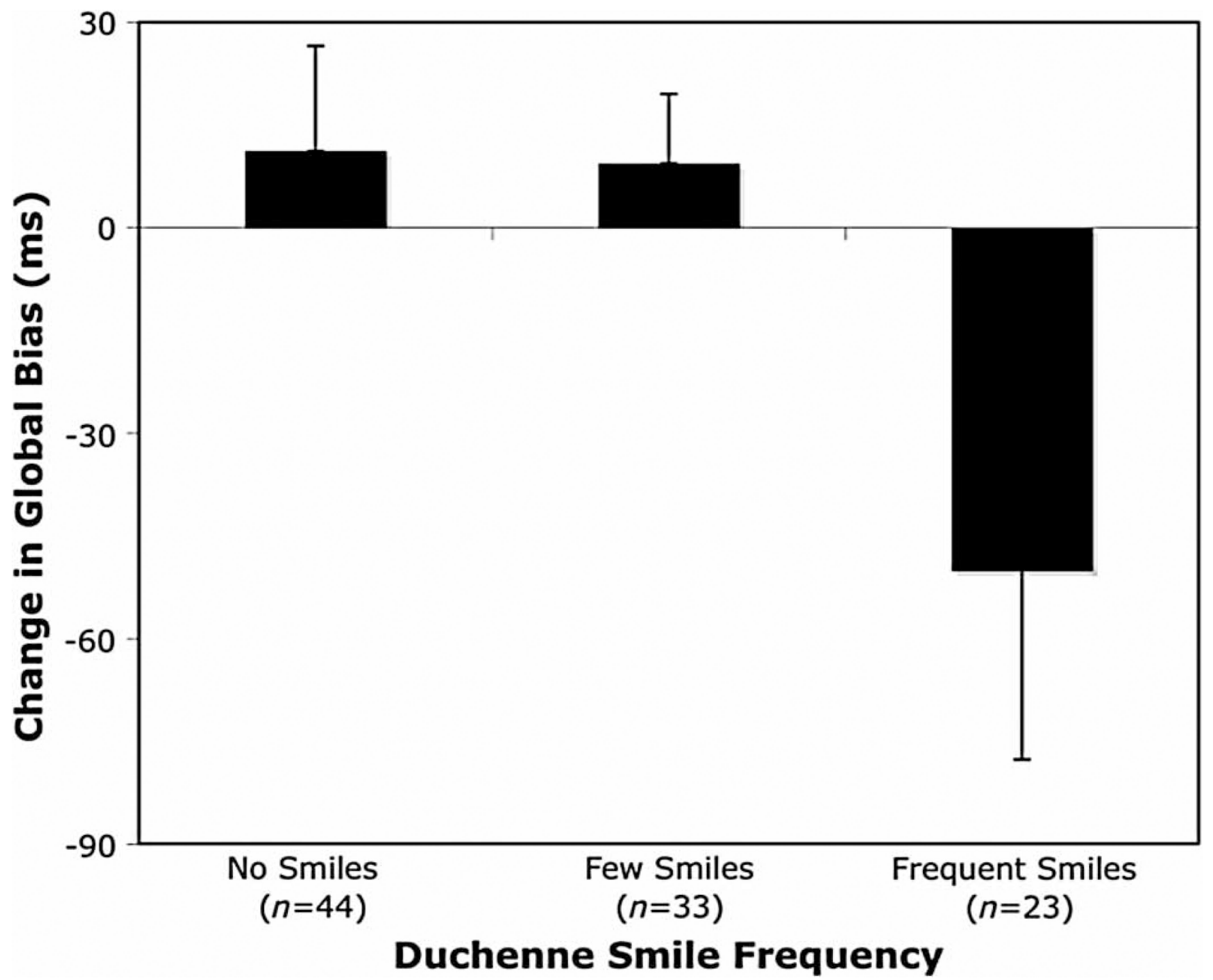

Figure 2.

Mean change in global bias as a function of Duchenne-smile frequency. Lower values indicate relatively faster responding to global targets. Error bars indicate the standard error of the mean. 


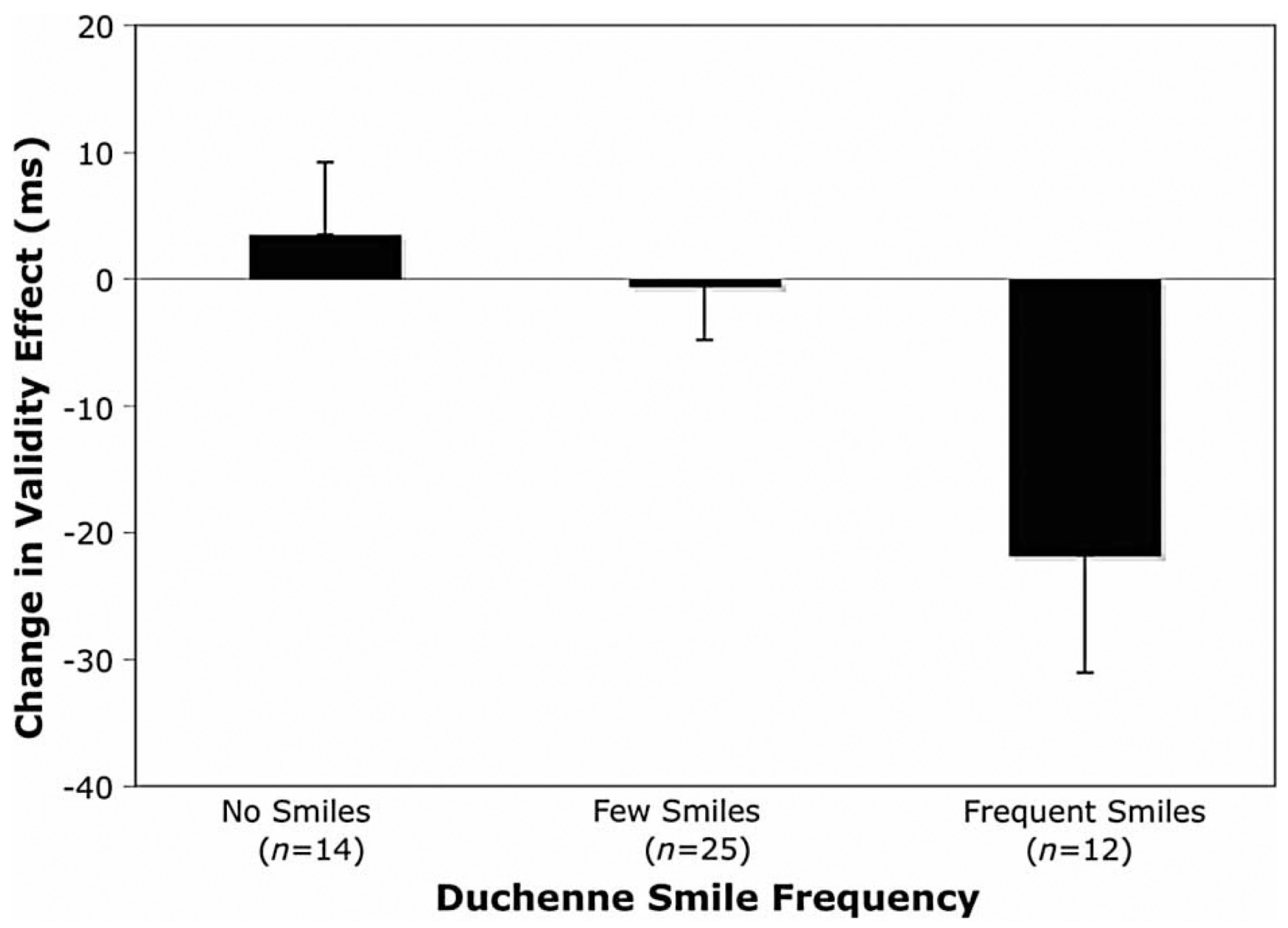

Figure 3.

Mean change in validity effect as a function of Duchenne-smile frequency. Lower values indicate decreased fixation to attentional cues. Error bars indicate the standard error of the mean. 


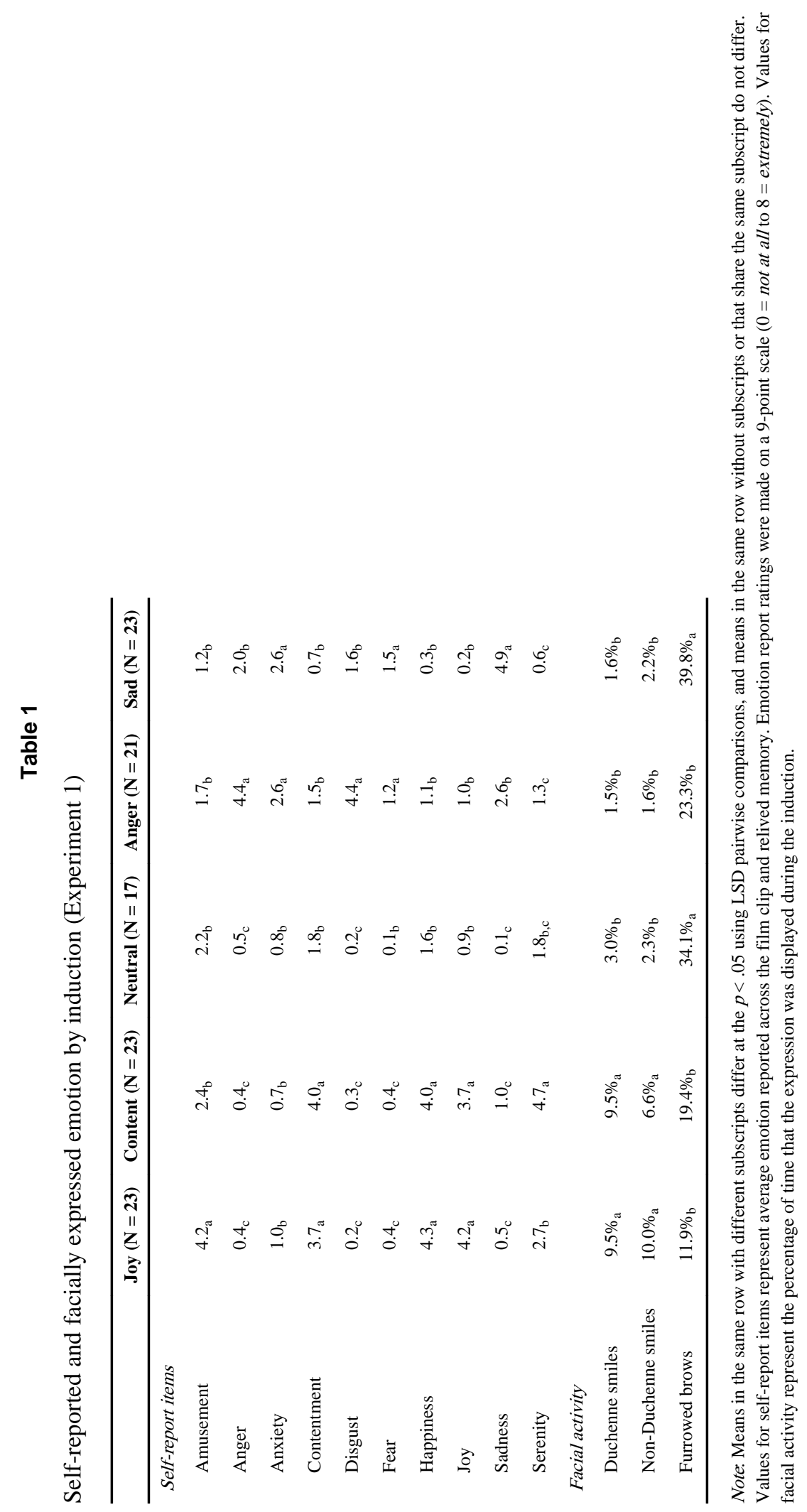




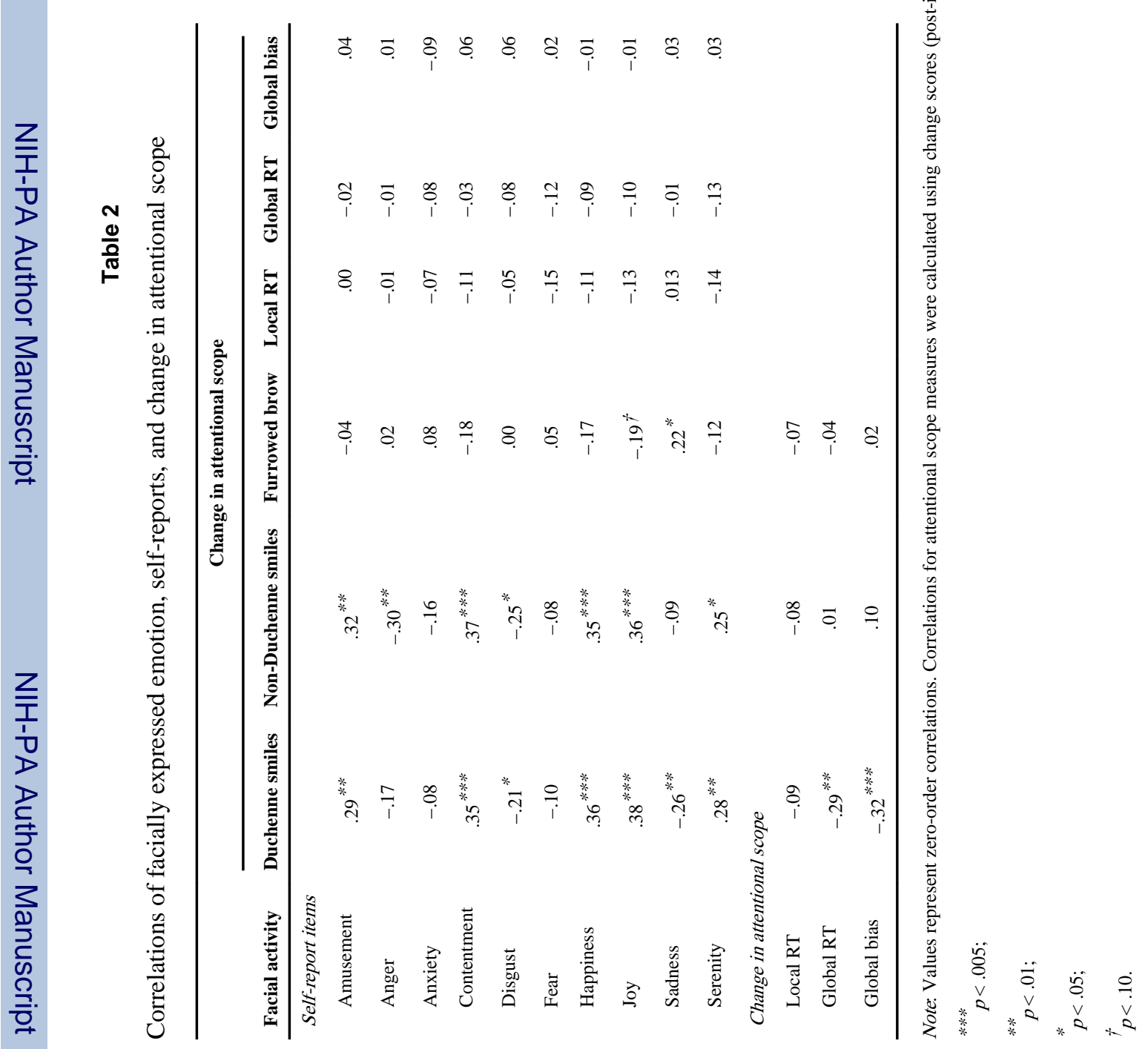


Table 3

Self-reported and facially expressed emotion by induction (Experiment 2)

\begin{tabular}{lccc}
\hline & $\begin{array}{c}\text { Elation } \\
(\mathbf{N}=17)\end{array}$ & $\begin{array}{c}\text { Neutral } \\
(\mathbf{N}=19)\end{array}$ & $\begin{array}{c}\text { Anger } \\
(\mathbf{N}=17)\end{array}$ \\
\hline Self-report items & & & \\
Amused & $0.2_{\mathrm{ab}}$ & $0.3_{\mathrm{b}}$ & $-0.8_{\mathrm{a}}$ \\
Angry & $-1.3_{\mathrm{a}}$ & $0.1_{\mathrm{b}}$ & $0.2_{\mathrm{b}}$ \\
Ashamed & $0.2_{\mathrm{b}}$ & $0.6_{\mathrm{a}}$ & $0.1_{\mathrm{b}}$ \\
Awe & $0 . \mathrm{b}_{\mathrm{b}}$ & $0.0_{\mathrm{b}}$ & $-0.9_{\mathrm{a}}$ \\
Compassion & -0.1 & -0.6 & 0.1 \\
Contempt & $-1.1_{\mathrm{a}}$ & $0.1_{\mathrm{b}}$ & $0.1_{\mathrm{b}}$ \\
Content & $0.1_{\mathrm{c}}$ & $-1.9_{\mathrm{a}}$ & $-0.9_{\mathrm{b}}$ \\
Disgust & $-0.9_{\mathrm{a}}$ & $0.1_{\mathrm{b}}$ & $0.6_{\mathrm{b}}$ \\
Embarrass & $1.4_{\mathrm{a}}$ & $1.4_{\mathrm{a}}$ & $0.5_{\mathrm{b}}$ \\
Grateful & -0.1 & -0.4 & -0.8 \\
Guilty & $-0.5_{\mathrm{a}}$ & $0.4_{\mathrm{b}}$ & $0.1_{\mathrm{b}}$ \\
Hopeful & $0.3_{\mathrm{b}}$ & $-0.1_{\mathrm{b}}$ & $-1.1_{\mathrm{a}}$ \\
Interest & -0.1 & 0.6 & -0.2 \\
Joy & $0.3_{\mathrm{b}}$ & $-0.9_{\mathrm{a}}$ & $-1.4_{\mathrm{a}}$ \\
Love & 0.1 & -0.6 & -0.3 \\
Proud & 0.5 & 0.4 & -0.3 \\
Sad & $-1.1_{\mathrm{a}}$ & $0.4_{\mathrm{b}}$ & $0.1_{\mathrm{b}}$ \\
Scared & 0.9 & 1.2 & 0.5 \\
Facial activity & & & \\
Duchenne smiles & $5.2 \%$ & $4.0 \%$ & $4.9 \%$ \\
Furrowed brow & $5.5 \%$ & $4.7 \%$ & $2.9 \%$ \\
& $26.1 \% \%_{\mathrm{a}}$ & $24.9 \%_{\mathrm{a}}$ \\
\hline & & \\
\hline
\end{tabular}

Note: Means in the same row with different subscripts differ at $p<.05$ using LSD pairwise comparisons, and means in the same row without subscripts or that share the same subscript do not differ. Values for emotion self-report items represent change in DES ratings from before to after the emotion induction (post-induction - pre-induction). DES ratings were made on a 5 -point scale $(0=$ not at all to $4=$ extremely). Values for facial activity represent the percentage of time that the expression was displayed during the induction. 
$\begin{array}{llll}\ddot{\theta} & & & \\ \dot{b} & \ddot{b} & \ddot{b} & \dot{O} \\ \dot{v} & \dot{v} & \dot{v} & \dot{v}\end{array}$ 